RESEARCH ARTICLE

\title{
Conducting polymer blends (polyaniline/polypyrrole) as counter electrode materials in dye sensitized solar cells
}

\author{
H.M.C.P. Nawarathna, D.U.S.N. Abeysingha, W.M.T.N. Wickramasinghe and W.S.S. Gunathilake* \\ Department of Chemistry, Faculty of Science, University of Peradeniya, Peradeniya 20400, Sri Lanka
}

Received:02/02/2018; Accepted:15/06/2018

\begin{abstract}
Dye sensitized solar cells have attracted lot of research interest in recent years due to their low production cost, higher transparency, easy fabrication and tunable optical properties. Generally, Platinum is used as the catalytic active counter electrode material in the cell which has achieved about $14.1 \%$ efficiency. Platinum is an expensive and rare metal and is susceptible to corrosion in long term applications. Therefore lot of research interest is focused on finding low cost, earth abundant alternatives as the counter electrode materials. Due to the low cost, higher conductivity, higher stability, easy preparation and easy fabrication, conducting polymers have become an advanced alternative. Generally, product performance of polymers has improved by blending two or more polymers. Conductivity, stability, structures and performances of pure polyaniline and pure polypyrrole are highly investigated. Among all counter electrode fabricated with conducting polymers, polyaniline has shown the highest power conversion efficiency in dye sensitized solar cells. Performance changes of dye sensitized solar cells have been discussed here by fabricating the counter electrode with polymer blends with different mass ratios of polyaniline and polypyyrole. Out of all the blends tested, polymer blend with 1:1 mass ratio of polyaniline:polypyrrole showed the lowest charge transfer resistance and highest efficiency in Dye-Sensitized Solar Cells.
\end{abstract}

Keywords: Conducting polymers, Counter electrode, DyeSensitized Solar Cells, Polymer blends.

\section{INTRODUCTION}

Solar cell is a photovoltaic cell which converts the light energy into electrical energy by photovoltaic effect. It contains both physical and chemical phenomena. Dye sensitized solar cell is a type of thin film solar cells with a low fabrication cost. The photo-electrochemical system of dye sensitized solar cell is composed of three main components viz., working electrode, an electrolyte and a counter electrode (Law et al., 2005). The cell has the ability to produce electricity in a wide range of light energies and it can operate under both artificial and natural light conditions. Further, they do not require pure materials and can be fabricated by simple fabrication techniques.

Counter electrode should have higher electrical conductivity for efficient charge transfer. Further, it acts as a catalyst and reduces the redox potential of the electrolyte. The potential reduction helps the efficient regeneration of sensitizer dye. Platinum $(\mathrm{Pt})$ is mostly used as a counter electrode due to its high catalytic activity and low resistance. However, $\mathrm{Pt}$ is an expensive material and its scarcity limits its applications. Apart from those, Pt has the possibility to undergo corrosion in the presence of the electrolyte solution.

To overcome these difficulties, many research work has been focused towards finding alternatives for Pt. Among them, conducting polymers and conducting polymer blends show high potential due to their high conductivity, low cost, easy preparation, good chemical stability and easy fabrication (Molapo et al., 2012). The major advantage of blending polymers is that it improves the product performance by changing the polymer properties such as morphology, modules, dimension stability, chemical resistance, and brittleness. It is also possible to form integrated multilayer structures by blending (Das et al., 1996).

Polyaniline is one of the highly investigated conducting polymers in dye sensitized solar cells as the counter electrode material. It has achieved the highest efficiency among all the other conducting polymers. The highest reported efficiency with polyaniline counter electrode is $8.1 \%$ (Muhammad et al., 2016). The highest efficiency of $7.6 \%$ has been reported with polypyrrole counter electrode (Muhammad et al., 2016). Both of these polymers are highly stable, conductive and easy to synthesize. However, the blend of polyaniline and polypyrrole as a counter electrode has not been reported so far and in this research the effect of the blends of these two polymers as counter electrode on the efficiency of dye-sensitized solar cells was investigated. Polymer blends were prepared by mixing the two polymers in different mass ratios.

\section{MATERIALS AND METHODS}

Aniline and pyrrole purchased from Sigma Aldrich were purified by distillation before using them in the experiment. All other chemicals were used without further purification unless otherwise noted.

\section{Preparation of solutions}

Titanium tetraisopropoxide $(1.0 \mathrm{ml})$, actyl acetone $(2.0$ $\mathrm{ml})$ and ethanol $(27.0 \mathrm{ml})$ were mixed in a beaker and ultrasonicated for 15 minutes at room temperature to 
prepare dense layer solution. To synthesize $\mathrm{TiO}_{2}$ colloidal solution, titanium tetraisopropoxide $(20.0 \mathrm{ml})$, acetic acid $(2.5 \mathrm{ml})$ and ethanol $(25.0 \mathrm{ml})$ were mixed together in a beaker. Steam was passed though the prepared mixture until it turned into light blue colour gel. After that, water $(50.0 \mathrm{ml})$ was added to the gel until it dissolved. Finally, the solution was autoclaved at $150.0^{\circ} \mathrm{C}$ for $3 \mathrm{~h}$. Then, $\mathrm{TiO}_{2}$ colloidal solution $(20.0 \mathrm{ml})$, glacial acetic acid $(5.5 \mathrm{ml})$, ethanol $(20.0 \mathrm{ml})$ and tritonX-100 (about 5 drops) were mixed in a beaker to prepare $\mathrm{TiO}_{2}$ spray solution.

\section{Preparation of working electrode}

First, FTO glasses were thoroughly washed with water, and ultra sonicated with detergent solution for $10 \mathrm{~min}$. The detergent solution was removed followed by ultra sonicating the glasses with ethanol for $10 \mathrm{~min}$ and dried well. Cleaned FTO glasses were heated up to $500{ }^{\circ} \mathrm{C}$ for $5 \mathrm{~min}$ before fabricating the dense layer by spray pyrolysis. Cells were maintained at $150{ }^{\circ} \mathrm{C}$ while spraying and fabricated cells were sintered at $500{ }^{\circ} \mathrm{C}$ for $30 \mathrm{~min}$. They were allowed to cool to room temperature and again heated up to $150{ }^{\circ} \mathrm{C}$ on a hot plate in order to deposit a mesoporous layer on top of the dense layer. $\mathrm{TiO}_{2}$ solution was sprayed on to the cell until white color thin layer of $\mathrm{TiO}_{2}$ was observed. Finally, cells were sintered at $500{ }^{\circ} \mathrm{C}$ for $30 \mathrm{~min}$.

\section{Preparation of the counter electrode}

\section{Preparation of polymers}

Interfacial chemical oxidative polymerization was used to synthesize polyaniline. Organic phase was prepared by dissolving aniline $(5.0 \mathrm{ml})$ in hexane $(500.0 \mathrm{ml})$. Aqueous phase was prepared by dissolving $\mathrm{K}_{2} \mathrm{~S}_{2} \mathrm{O}_{8(\mathrm{~s})}(3.410 \mathrm{~g})$ in $1 \mathrm{M}$ $\mathrm{HCl}_{(\mathrm{aq})}(500.0 \mathrm{ml})$. After that, two solutions were mixed together in reagent bottle and allowed to stand for $24 \mathrm{~h}$ (Zhang et al., 2004).

Then, the green coloured product was separated by filtration. Filtrated product was doped with $\mathrm{HCl}$ by stirring the polymer in $1 \mathrm{M} \mathrm{HCl}$ for overnight. Finally, doped product was separated and washed with water to remove excess dopants (E. C. Gomes, M. A. S. Oliveira., 2012). Polypyrrole was also prepared by using conventional chemical oxidative polymerization method. Pyrrole (3.4 $\mathrm{ml})$ was dissolved in ethanol $(25.0 \mathrm{ml})$ by stirring. Then 0.5 $\mathrm{M} \mathrm{FeCl}_{3} \cdot 6 \mathrm{H}_{2} \mathrm{O}_{\text {(aq) }}(25.0 \mathrm{ml})$ was slowly added to the pyrrole solution while stirring. Finally, the mixture was stirred for $24 \mathrm{~h}$ and the product was separated by filtration.

\section{Preparation of polymer blends and fabrication of the counter electrode}

Different mass ratios of the polyaniline and polypyrrole (Table 1) were mixed in $1 \mathrm{M} \mathrm{HCl}$ medium by stirring for $24 \mathrm{~h}$. Then the mixture was filtered to separate the polymer blend which was then washed with water to remove excess dopants and dried at $80{ }^{\circ} \mathrm{C}$. The blend paste was prepared by adding $10 \%$ of ethyl cellulose binder by mass of polymer and mixed with terpinol (5 drops) and ethanol (5 drops). Then the mixture was grinded well using motor and pestle. The final blend was screen printed on cleaned FTO glass to fabricate the counter electrode.

\section{Instrumentation}

Polymers and polymer blends were characterized by using Fourier Transform Infrared Spectrometer (ModelShimandu Prestige-21), Particle Size Analyzer (Dual scattering PSA NANO DS CILAS), and Scanning Electron Microscope (Model No. EVOLS15). Characterization of the cathodes were done by Auto-Lab (Model No. PGSTAT12). Current-voltage (I-V) characteristics of the cells at AM $1.5\left(100 \mathrm{~mW} \mathrm{~cm}^{-2}\right)$ simulated sunlight irradiation were recorded with a calibrated solar-cell evaluation system, Solar Simulator (Model No. PECell-PECL01).

\section{RESULTS AND DISCUSSION}

\section{Characterization of polymers}

Polymer characterization was carried out by analyzing physical properties using Fourier Transform Infrared Spectroscopy (FTIR), particle size analysis and Scanning Electron Microscopy (SEM). The conducting form of polyaniline and polypyrrole were confirmed by using their characteristic dark green and black colors, respectively. The conducting form of polyaniline which is 'Emarladine salt' can be easily identified by its characteristic green color. The other two forms, leucoemeraldine and pernigraniline, are yellow/white and purple in color, respectively

Table 1: Mass ratios that used for polymer blends.

\begin{tabular}{cccc}
\hline Polymer blends & Mass of Ployaniline/g & Mass of Polypyrrole/g & Mass ratio \\
\hline A & 1.000 & 0.100 & $10: 1$ \\
\hline B & 0.800 & 0.200 & $8: 2$ \\
\hline C & 0.700 & 0.300 & $7: 3$ \\
\hline D & 0.600 & 0.400 & $6: 4$ \\
\hline E & 0.500 & 0.500 & $5: 5$ \\
\hline F & 0.400 & 0.600 & $4: 6$ \\
\hline G & 0.300 & 0.700 & $3: 7$ \\
\hline H & 0.200 & 0.800 & $2: 8$ \\
\hline I & 0.100 & 1.000 & $1: 10$ \\
\hline
\end{tabular}




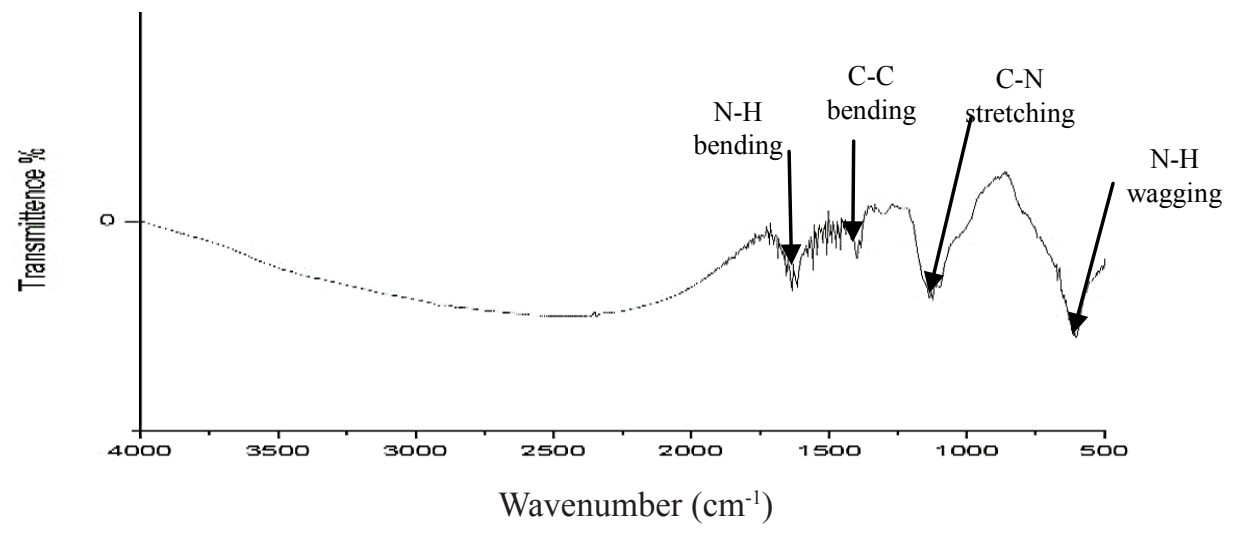

Figure 1: FTIR curve of the synthesized polyaniline.

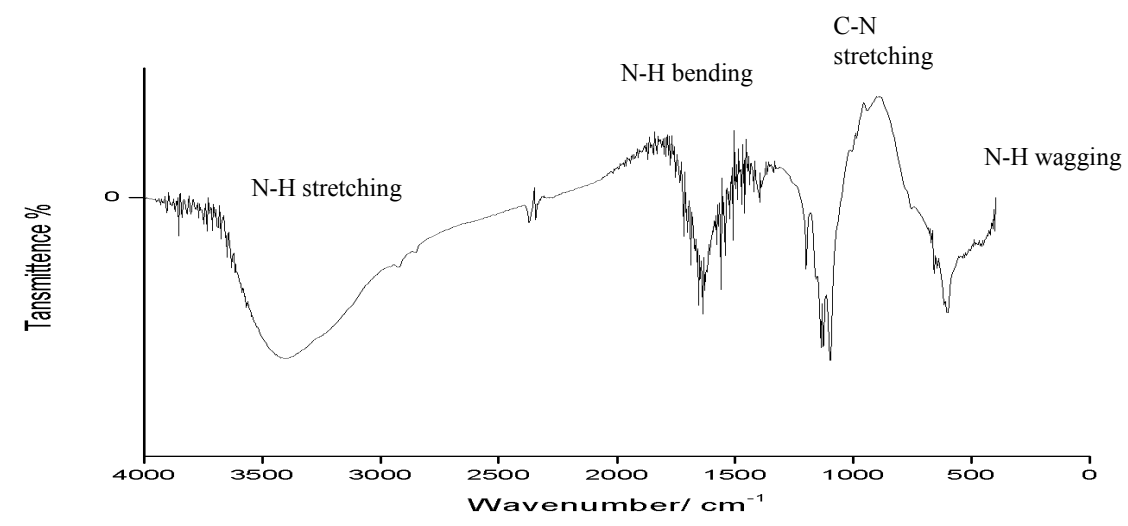

Figure 2: FTIR curve of the synthesized polypyrrole.
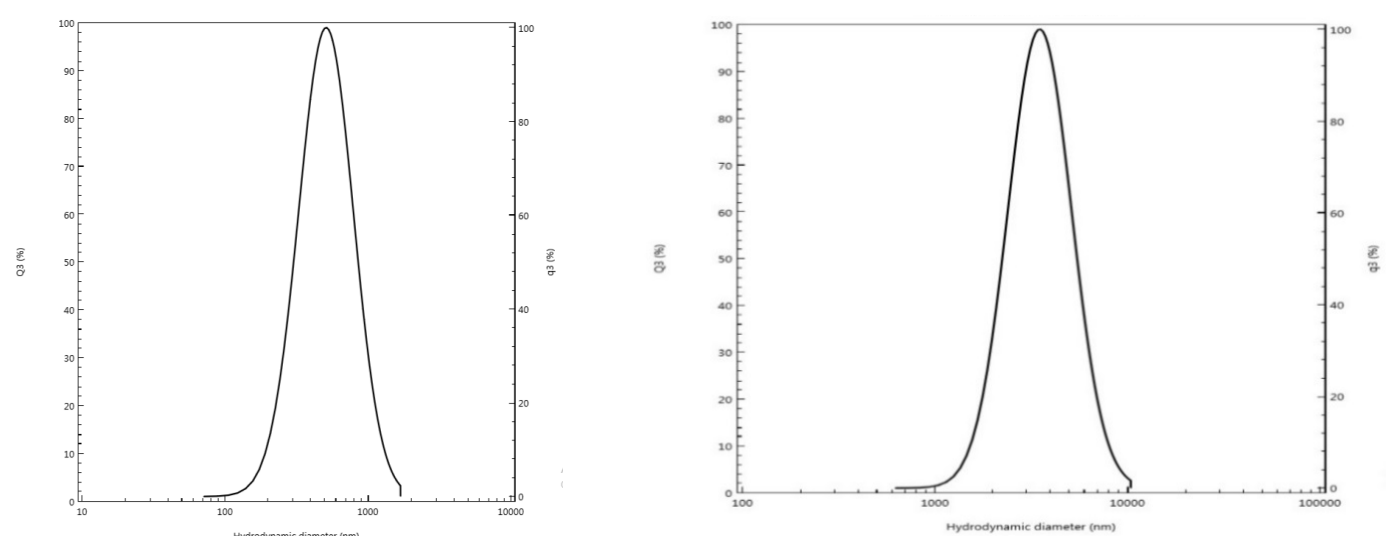

Figure 3: Particle size distribution of (a) Polyaniline, (b) Polypyrrole.

(Kerileng et al., 2012). The polyaniline synthesized by chemical oxidation of aniline by $\mathrm{K}_{2} \mathrm{~S}_{2} \mathrm{O}_{8(\mathrm{~s})}$ had green color which indicates the formation of conducting (ES) form of polyaniline. Polypyrole was obtained as a black color powder which is only one form of polypyrrole and is conducting because of the availability of $\pi$ - conjugated polymer backbone. (Anzari, 2006)

According to the figure 1, characteristic peaks for polyaniline can be clearly seen in the FTIR spectrum obtained for the product. Further, almost all the peaks overlap with the peaks of reference curve of polyaniline reported in the literature (Tang et al., 1988).

The peak around $1600 \mathrm{~cm}^{-1}$ can be attributed to the N-H bending vibration and peak of $1400 \mathrm{~cm}^{-1}$ could be because of C-C bending vibrations. The peak at $1150 \mathrm{~cm}^{-1}$ and 690 $\mathrm{cm}^{-1}$ is due to $\mathrm{C}-\mathrm{N}$ stretching and $\mathrm{N}-\mathrm{H}$ wagging vibrations. The presence of peaks around $1600 \mathrm{~cm}^{-1}$ and $1400 \mathrm{~cm}^{-1}$ further confirms the presence of quinoid and benzoid units in emeraldine salt form of polyaniline.

Characteristics peaks for polypyrrole can be seen in the FTIR spectrum of the synthesized product(figurer 2). Further, almost all the peaks were overlapped with the reference spectrum of polypyrrole (Bhat et al., 2001). In the FTIR spectrum at figure 2, N-H starching peak can be seen around $3,250-3,500 \mathrm{~cm}^{-1}$. This peak overlaps with the O-H starching frequency of adsorbed water, which can be seen in the same range.

According to figure 3 , it can be said that both polyaniline 

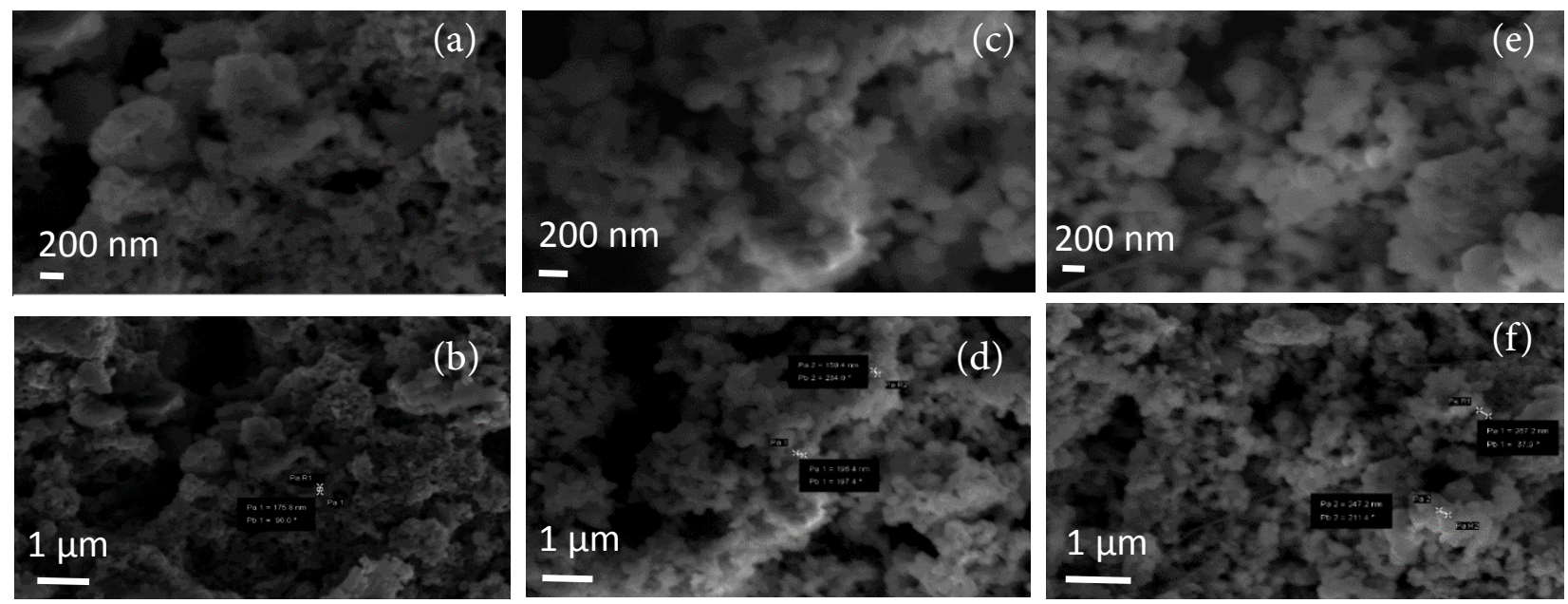

Figure 4: SEM images of (a). Pure polyaniline $(\times 50000)$, (b). pure polyaniline $(\times 25000)$, (c). pure polypyrrol $(\times 50000)$, $(d)$. Pure polypyrrole $(\times 25000)$, (e). 1:1 polymer blend $(\times 50000)$, (f). 1:1 polymer blend $(\times 25000)$.
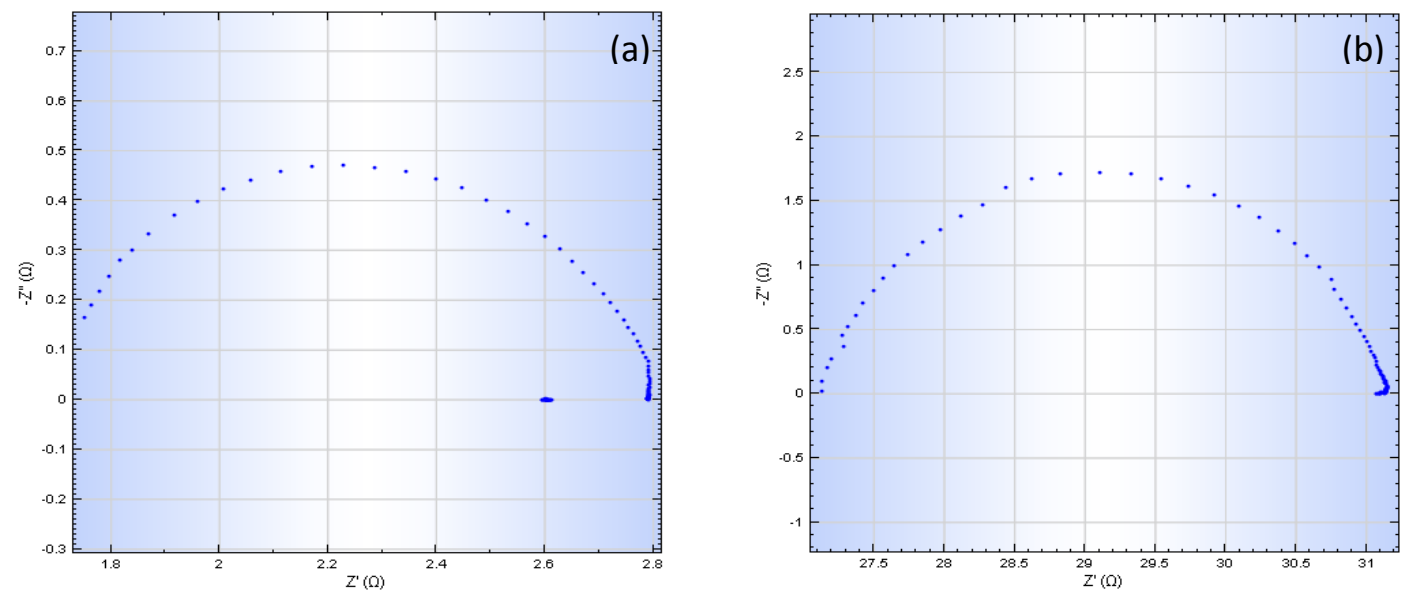

Figure 5: Impedance spectrum (a) Pt cathode, (b) 1:1 ratio of polyaniline to polypyrrole fabricated cathode.

and polypyrrole particles are in the same size range. Only one peak is present in both cases. The particle size given by the particle size analyzer is somewhat larger than the actual particle size of the polymer particles. Because, particle size analyzer gives the hydrodynamic radius of the particles. Water molecules aggregate around the polymer particle and prepare a globular shaperical structure. Detector of the instrument detects the radius of that globular shape structure. Further, the sizes obtained from particle size analyzer for both polymers are significantly larger than that obtained with SEM which could also be because of the above mentioned reason.

Scanning electron microscopic images given in figure 4 , both polyaniline and polypyrrole show granular shape particles. The particle diameter of polyaniline is around 175 $\mathrm{nm}$ and particle diameter of polypyrrole is around $195 \mathrm{~nm}$. In both polymers particle diameters are almost similar and it is in the range of $150 \mathrm{~nm}-200 \mathrm{~nm}$. Polymer blend also showed granular shape particles with similar diameters.

\section{Cathode characterization}

According to electrochemical impedance spectroscopic studies of the cathodes fabricated with polymer blends, only one curve can be seen in the spectra. The reason is, both of these spectra were taken for the symmetric cells, which means, impedance spectrum was taken by placing electrolyte solution in between two identical cathodes. Due to that, the system contains only two types of resistances. One of them is the charge transfer resistance and the other one is diffusion resistance. Diffusion resistance is very low for the electrolyte solution which contains $\mathrm{I}^{-} / \mathrm{I}_{3}^{-}$redox couple. Therefore, the corresponding curve for diffusion resistance cannot be seen in the spectrum. The observable curve is for charge transfer resistance. The charge transfer resistance values indicate the resistance for the electrons to transit between counter electrode surface and the electrolyte solution. Lower charge transfer resistance increases the cell performance.

\section{Electrochemical Impedance Spectroscopy}

According to the results obtained, the charge transfer resistance between $\mathrm{Pt}$ surface and electrolyte is $1.1 \Omega$ and that of polyaniline:polypyrrole (1:1 mass ratio) polymer blend cathode is about $4.1 \Omega$. The charge transfer resistance of polymer blend is not much deviated from Pt cathode. The calculated charge transfer resistance values for all the other polymer blends are given in the table 2. Pt has the lowest charge transfer resistance and next lowest value was obtained for the 1:1 polymer blend. This value is lower than that of both pure polymers. All the polymer blends except the blend of with 2:8 mass ratio of polyaniline:polypyrrole 
Table No 2: Charge transfer resistance of different cathodes.

\begin{tabular}{|c|c|}
\hline Cathode & Resistance/ $\boldsymbol{\Omega}$ \\
\hline $\mathrm{Pt}$ & 1.1 \\
\hline Polyaniline & 340 \\
\hline Polypyrrole & 850 \\
\hline $\mathbf{E}$ & $\mathbf{4 . 1}$ \\
\hline $\mathrm{D}$ & 29 \\
\hline $\mathrm{C}$ & 118 \\
\hline $\mathrm{B}$ & 115 \\
\hline F & 68 \\
\hline $\mathrm{G}$ & 92 \\
\hline $\mathrm{H}$ & 660 \\
\hline
\end{tabular}

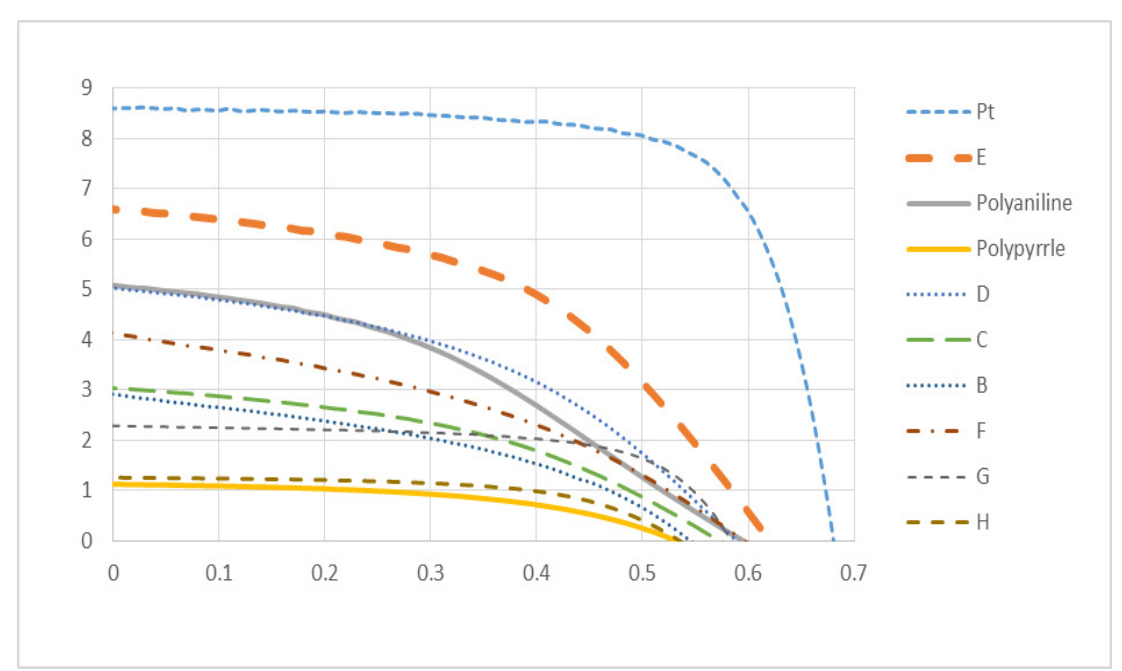

Figure 6: Current-Voltage characterization curves for dye sensitized solar cells containing different types of cathodes.

showed lower charge transfer resistance than individual homopolymers. This decrease in resistance could be due to the incensement of conductivity of the polymer blends. Higher conductivity can be obtained by mixing similar masses of polyaniline and polypyrrole. It could be because of decreasing the band gap between valence band and conduction band due to the blending of Highest Occupied Molecular Orbital (HOMO) and Lowest Unoccupied Molecular Orbital (LUMO) of the two polymers. Although a systematic change in the charge transfer resistance was not observed with changing the polymer composition, the deviation of the charge transfer resistance from the highest value is small when the mass ratio of the two polymers is closer to $1: 1$. For an example the second lowest charge transfer resistance value of $29 \Omega$ was observed with $6: 4$ ratio and third lowest value, which is, $68 \Omega$ was observed with 4:6 polymer ratio in the blend. This could be because of the better mixing of the two polymers when the ratio is $1: 1$ and closer to $1: 1$.

\section{Current-Voltage characterization}

Maximum current density and maximum voltage values for the cell containing 1:1 polyaniline:polypyrrole polymer blend (E) were $6.57 \mathrm{~mA} \mathrm{~cm}^{-1}$ and $0.62 \mathrm{~V}$ respectively. These values for the standard cell were $8.58 \mathrm{~mA} \mathrm{~cm}^{-1}$ and $0.68 \mathrm{~V}$. These values suggest that, the cell containing alternative cathode out- put is not much deviated from the standard cell.
According to the figure 6 and table 3 shown above, the highest efficiency can be seen for Pt cathode with highest $V_{\text {oc }}, J_{\text {sc }}$ and fill factor. These results are due to the higher catalytic activity and higher conductivity of Pt. Polymer blend with 1:1 mass ratio has the next highest efficiency value. However the current is lower for the polymer blend because of the conductivity of polymers compare to metals. Further, the fill factor is also lower for the polymer blend compared to Pt which could be because of the poor contacts and rough surface of fabricated polymer. The surface of the fabricated polymer layer is not uniform as the Pt surface. The lower efficiency of the polymer blend $\mathbf{E}$ compared to Pt can be because of the lower catalytic activity of the polymer blend. Although $\mathrm{Pt}$ is a catalyst towards $\mathrm{I}^{-} / \mathrm{I}_{3}^{-}$redox couple, it has not been reported that polyaniline/polypyrrole polymer blend is a catalyst towards this redox couple. This may be a reason for the considerable efficiency value difference with Pt cathode.

The variations of cell performance in different polymer blend cathodes display a comparable trend with impedance studies. This trend clearly shows the relationship between the charge transfer resistance and the cell performance. Comparatively higher efficiency values have given for the polymer blends containing similar masses of polyaniline and polypyrrole.

Generally, ethyl cellulose binder is perfectly performed on polyaniline and its binding ability on polypyrrole is somewhat weaker. Therefore, pure polyaniline layer is 
Table 3: Current- voltage characteristics of dye sensitized solar cells containing different types of cathodes.

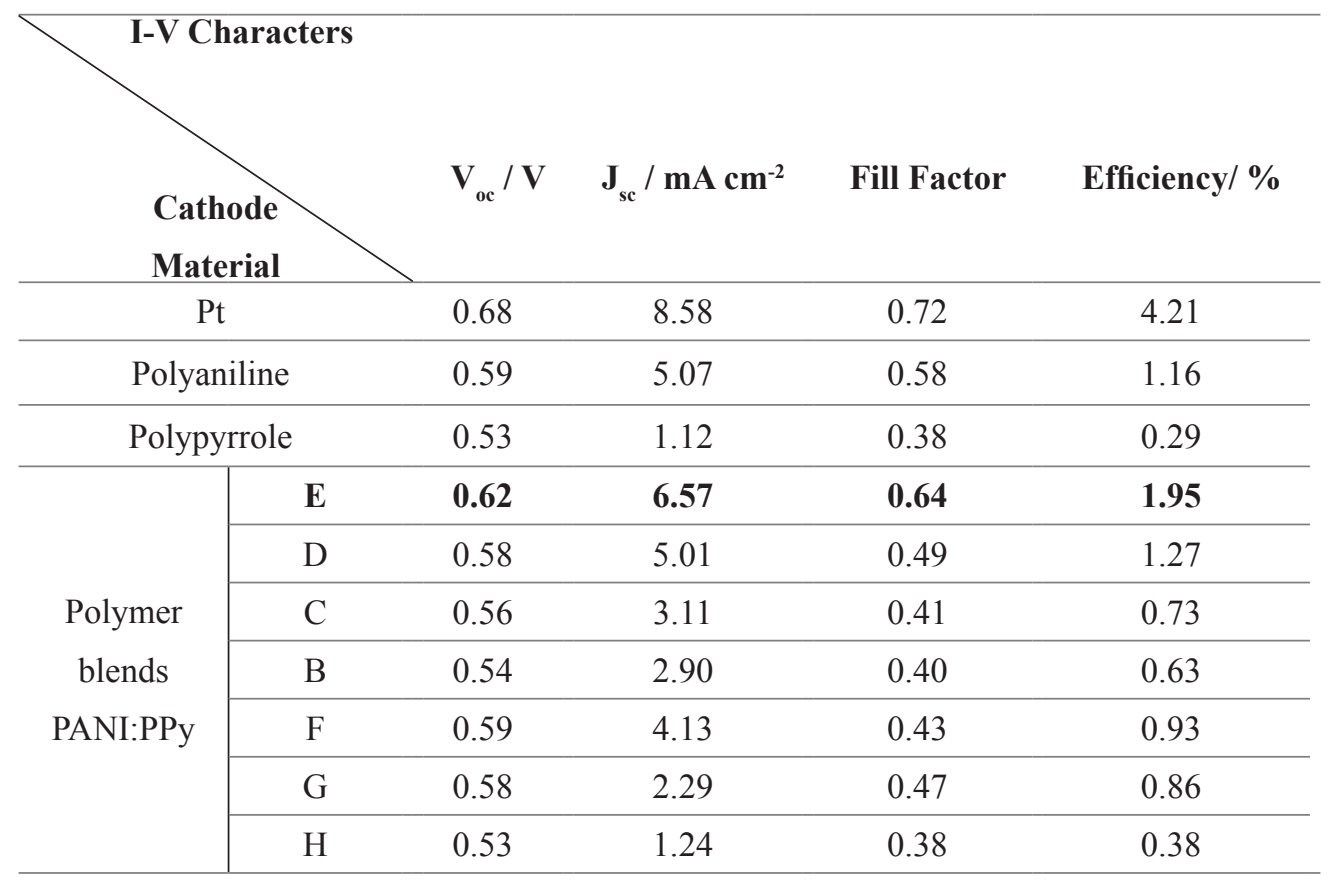

perfectly binds on the FTO glass surface than other blends. Efficiency value for all the cells which contains polymer blend cathode can be further increased by optimizing the amount of binder.

\section{CONCLUSION}

Conducting forms of polyaniline was synthesized by interfacial chemical oxidative polymerization by using the $\mathrm{K}_{2} \mathrm{~S}_{2} \mathrm{O}_{3}$ as the oxidant. Polyaniline and polypyrrole blends were prepared by blending the polyaniline with polypyrrole which was synthesized by chemical oxidative polymerization by using $\mathrm{FeCl}_{3}$ as the oxidant. Both polymer particles were granular in shape and their particle diameters are in 150-200 nm range. Polymer blend with polyaniline:polypyrrole (1:1) mass ratio showed the lower charge transfer resistance and higher solar energy to light energy conversion efficiency than cathode containing pure polymers. Polymer blends is better alternative than the pure polymer form of polyaniline and polypyrrole as the cathode material in the dye sensitized solar cells.

\section{REFERENCES}

Cakmak, G., Kü,ükyavuz, Z. and Küükyavuz, S. (2005). Conductive copolymers of polyaniline, polypyrrole and poly(dimethylsiloxane). Synthetic Metals 151(1): 10-18. https://doi.org/10.1016/j.synthmet.2005.02.019.

Cesiulis, H., Tsyntsaru, N., Ramanavicius, A. and Ragoisha, G. (2016). Nanostructures and Thin Films for Multifunctional Applications. Springer, Cham. Pp. 3-42. https://doi.org/10.1007/978-3-319-30198-3.

Han, L., Koide, N., Chiba, Y., Islam, A.and Mitate, T. (2006). Modeling of an equivalent circuit for dyesensitized solar cells: improvement of efficiency of dyesensitized solar cells by reducing internal resistance. Comptes Rendus Chimie 9(5-6): 645-651. https://doi. org/10.1016/j.crci.2005.02.046.
Jasim, K. E. (2007). Dye sensitised solar cells-working principles, challenges and opportunities. Dye Sensitized Solar Cells-Working Principles, ChallengesPp171-204. Retrieved from http://www.intechopen.com/source/ pdfs/23333/InTech-Dye sensitized solar cells working_principles_challenges_and_opportunities.pdf.

Lu, S., Wang, S., Han, R., Feng, T., Guo, L., Zhang, X., Liu, D. and He, T. (2014). The working mechanism and performance of polypyrrole as a counter electrode for dye-sensitized solar cells. Journal of Materials Chemistry A2 (32): 12805-12811. https://doi. org/10.1039/C4TA02193B.

McCullough, L. A., Dufour, B. and Matyjaszewski, K. (2009). Polyaniline and polypyrrole templated on selfassembled acidic block copolymers. Macromolecules 42(21): 8129-8137. https://doi.org/10.1021/ ma901560k.

Molapo, K. M., Ndangili, P. M., Ajayi, R. F., Mbambisa, G., Mailu, S. M., Njomo, N., Masikini, M., Baker, P. and Iwuoha, E. I. (2012). Electronics of conjugated polymers (I): Polyaniline. International Journal of Electrochemical Science 7(12): 11859-11875.

Qi, G., Huang, L., and Wang, H. (2012). Highly conductive free standing polypyrrole films prepared by freezing interfacial polymerization. Chemical Communications 48(66): 8246. https://doi.org/10.1039/c2cc33889k.

Rahman, M. S., Hammed, W. A., Yahya, R. B. and Mahmud, H. N. M. E. (2016). Prospects of conducting polymer and graphene as counter electrodes in dye-sensitized solar cells. Journal of Polymer Research 23(9). https:// doi.org/10.1007/s10965-016-1090-6.

Reung-U-Rai, A., Prom-Jun, A., PrissanaroonOuajai, W.and Ouajai, S. (2008). Synthesis of Highly Conductive Polypyrrole Nanoparticles via Microemulsion Polymerization. Journal of Metals, Materials and Minerals 18(2): 27-31. https://doi. org/10.1002/app.34714. 